\title{
Spatiotemporal distribution of very-low frequency earthquakes in Tokachi-oki near the junction of the Kuril and Japan trenches revealed by using array signal processing
}

\author{
Youichi Asano $^{1}$, Kazushige Obara ${ }^{1}$, and Yoshihiro Ito ${ }^{2}$ \\ ${ }^{1}$ National Research Institute for Earth Science and Disaster Prevention, Ten-nodai 3-1, Tsukuba 305-0006, Japan \\ ${ }^{2}$ Research Center for Prediction of Earthquakes and Volcanic Eruptions, Graduate School of Science, Tohoku University, \\ Aramaki-aza-aoba, Aoba-ku, Sendai 980-8578, Japan
}

(Received March 12, 2008; Revised April 24, 2008; Accepted April 29, 2008; Online published September 8, 2008)

\begin{abstract}
We have developed a signal-processing method for array data recorded at densely and widely distributed tiltmeter stations in Japan and analyzed the data recorded during the last 5 years. Filtered seismograms were analyzed to detect coherent seismic waves and estimate the epicenters. In order to identify very-low frequency earthquakes (VLFEs) with only low-frequency energies only, we selected only events not listed in the earthquake catalogue provided by the Japan Meteorological Agency from all of the detected events. The epicenters of the obtained VLFEs were estimated to be distributed not only along the Nankai Trough, where the events occurred on the reverse faults in the well-developed accretionary prism, but also in Tokachi-oki without accretion. This result suggests that even in such a region, VLFEs can occur on a shallower portion of the plate boundary than the seismogenic region of ordinary earthquakes and/or in a deformed area of the overriding plate along the subduction zone without accretion.
\end{abstract}

Key words: Very-low frequency earthquake, array signal processing, subduction, Tokachi-oki.

\section{Introduction}

The development of seismograph networks in the last 10 years has contributed to the discovery of new types of seismic phenomena, such as non-volcanic tremors (Obara, 2002) and very-low frequency earthquakes (VLFEs) (e.g., Obara and Ito, 2005; Ito et al., 2007). Obara and Ito (2005) investigated the spatial distribution of VLFEs along the Nankai Trough (NT) and showed that several clusters of VLFE activities were distributed along the trough. Ito and Obara (2006) estimated the centroid moment tensors of VLFEs and showed that the centroids were distributed in accretionary prisms along the trough and that the focal mechanisms were consistent with the faults in the prisms. These studies have increased our understanding of the activities and the occurrence mechanism of VLFEs along the NT. However, it is not known whether such types of VLFEs occur only along the NT with developed accretionary prisms because VLFE activity has not been investigated with a homogeneous detectability in time and space domains. Consequently, we have been attempting to automatically detect and locate VLFEs in and around Japan with homogeneous detectability and to investigate the spatiotemporal activities of VLFEs. The activities that are being detected will provide us with important information to discuss the occurrence mechanism of VLFEs and also reveal the factor that controls these activities.

Copyright (c) The Society of Geomagnetism and Earth, Planetary and Space Sciences (SGEPSS); The Seismological Society of Japan; The Volcanological Society of Japan; The Geodetic Society of Japan; The Japanese Society for Planetary Sciences; TERRAPUB.
Signals from VLFEs do not have clear $P$ - and $S$ wave arrivals and, therefore, it is difficult to locate these earthquakes using the ordinary hypocenter determination method. However, even in the case of VLFEs, array signal processing is sometimes effective in detecting and locating events, provided the stations are sufficiently dense to sample the seismic waves without aliasing. Here, we propose a method to detect and locate events from data recorded at densely and widely distributed seismograph networks.

\section{Method}

Seismograms observed at stations with a station separation smaller than the wavelength of interest are quite coherent, while those observed at stations with a station separation larger than several times the wavelength are often incoherent, mainly due to the heterogeneity in the crust and mantle. We introduced a two-step signal processing method to deal with data observed at widely distributed stations. In the first step, seismograms observed at a large number of arrays with an aperture that is one- to two-fold larger than the wavelength are analyzed by the conventional stacking method for evaluating the semblance coefficient (Neidell and Taner, 1971) in order to detect coherent waves and to estimate the apparent slowness vectors of the propagating waves. In the second step, the epicenter location that explains the apparent slowness vectors at these arrays is estimated. 
The semblance $C_{i}\left(t_{j}\right)$ in the $i$-th array and at the $j$-th time step for a reference time $t_{j}$ is described as

$$
\begin{aligned}
C_{i}\left(t_{j}\right)= & \sum_{k=1}^{K}\left(\sum_{l=1}^{L}\left(A_{i l}\left(t_{j}+k t^{\mathrm{sample}}+d t_{i l}\left(\mathbf{S}_{i}\left(t_{j}\right)\right)\right)\right)\right)^{2} \\
& / L \sum_{k=1}^{K} \sum_{l=1}^{L}\left(A_{i l}\left(t_{j}+k t^{\mathrm{sample}}+d t_{i l}\left(\mathbf{S}_{i}\left(t_{j}\right)\right)\right)\right)^{2},
\end{aligned}
$$

where $A_{i l}(t)$ is the amplitude observed at the $l$-th station of the $i$-th array at time $t ; k, t^{\text {sample }}$, and $d t_{i l}\left(\mathbf{S}_{i}\left(t_{j}\right)\right)$ represent the sample number in the time window, sampling rate, and travel-time difference at the $l$-th station from the reference point for an assumed horizontal apparent slowness vector $\mathbf{S}_{i}\left(t_{j}\right)$ of the seismic wave propagating in the $i$-th array at the $j$-th time step, respectively; $L$ and $K$ are the number of stations in the array and the window length of samples, respectively. The apparent slowness vector of the propagating wave $\mathbf{S}_{i j}^{\text {est }}$ that maximizes the semblance $C_{i}\left(t_{j}\right)$ in the $i$-th array and at the $j$-th time step can be estimated for each array and time step using the grid search algorithm.

In the case of seismic waves radiated from a hypocenter, we can estimate the epicenter location that explains these apparent slowness vectors in the arrays. In order to evaluate the extent to which the observed vectors match the modelpredicted vectors, we introduced a cylindrical-wave index $\theta^{\text {cyl }}\left(t_{j}\right)$ that is defined by

$$
\theta^{\mathrm{cyl}}\left(t_{j}\right)=\sum_{i=1}^{I} w_{i}\left(t_{j}\right) \mathbf{U}_{i}^{\mathrm{obs}}\left(t_{j}\right) \cdot \mathbf{U}_{i}^{\mathrm{prd}}\left(t_{j}\right) / \sum_{i=1}^{I} w_{i}\left(t_{j}\right),
$$

where $I$ is the number of arrays; $\mathbf{U}_{i}^{\text {obs }}\left(t_{j}\right)$ and $\mathbf{U}_{i}^{\text {prd }}\left(t_{j}\right)$ are the observed and model-predicted unit vectors, respectively, and these unit vectors are the apparent slowness vectors normalized by their lengths, representing the azimuths of the wave propagation direction. These unit vectors are represented as

$$
\mathbf{U}_{i}^{\mathrm{obs}}\left(t_{j}\right)=\mathbf{S}_{i}^{\mathrm{est}}\left(t_{j}\right) /\left|\mathbf{S}_{i}^{\mathrm{est}}\left(t_{j}\right)\right|
$$

and

$$
\mathbf{U}_{i}^{\mathrm{prd}}\left(t_{j}\right)=\left(\mathbf{X}_{i}^{\mathrm{array}}-\mathbf{X}^{\mathrm{epi}}\left(t_{j}\right)\right) /\left|\mathbf{X}_{i}^{\mathrm{array}}-\mathbf{X}^{\mathrm{epi}}\left(t_{j}\right)\right|,
$$

respectively. $\mathbf{X}_{i}^{\text {array }}$ and $\mathbf{X}^{\mathrm{epi}}\left(t_{j}\right)$ are the horizontal locations of the $i$-th array and the epicenter assumed for the $j$-th time step, respectively. In Eq. (2), the inner products of the observed and model-predicted unit vectors are averaged over all the arrays with the weight factor $w_{i}\left(t_{j}\right)$, which is defined as follows:

$$
\begin{aligned}
& w_{i}\left(t_{j}\right)=C_{i}\left(t_{j}\right) /\left|\mathbf{X}_{i}^{\text {array }}-\mathbf{X}^{\mathrm{epi}}\left(t_{j}\right)\right| \text { for } C_{i}\left(t_{j}\right) \geq 0.5, \\
& w_{i}\left(t_{j}\right)=0 \quad \text { elsewhere. }
\end{aligned}
$$

This weight factor depends on the epicentral distance and semblance to reduce the weight for uncertain data corresponding to a low semblance in an array far from the epicenter.
The optimum epicenter location with the maximum cylindrical-wave index is estimated using the grid search algorithm and steepest descent method (e.g., Press et al., 1989) in order to prevent the estimated epicenter from being trapped local maximizations. The grossly estimated epicenter location by the grid search algorithm is selected to be an initial model for the steepest descent method in which the epicenter location model is iteratively modified until the cylindrical-wave index becomes sufficiently large.

A large cylindrical-wave index close to 1 means that the observed vectors are well explained by the model-predicted vectors; however, this does not imply the uniqueness of the estimated epicenter location. Subsequently, we also introduced a plane-wave index to evaluate the goodness of data coverage, which is defined as

$$
\theta^{\mathrm{pln}}\left(t_{j}\right)=\left|\sum_{i=1}^{I} w_{i}\left(t_{j}\right) \mathbf{U}_{i}^{\mathrm{obs}}\left(t_{j}\right)\right| / \sum_{i=1}^{I} w_{i}\left(t_{j}\right) .
$$

This index represents a type of variance in observed azimuths distributed around their average. If the plane-wave index is close to 0 , the observed azimuths are distributed in various directions. Thus, we can detect coherent waves, estimate the original epicenter locations, and obtain only accurate locations by selecting epicenters with not only larger cylindrical-wave indexes but also smaller plane-wave indexes.

\section{Data and Analysis}

In this study, seismograms observed during the period of July 2003 to December 2007 were analyzed; the seismograms were observed by a tiltmeter network (Hi-net TILT) (Obara et al., 2005) consisting of 722 stations with a 20- to $30-\mathrm{km}$ spacing between stations. We composed 110 arrays with an aperture of about $100 \mathrm{~km}$; each array had 10-32 stations. A band-pass filter with a pass-band of $0.02-0.05 \mathrm{~Hz}$ was applied to the original seismograms sampled with a frequency of $20 \mathrm{~Hz}$; the filtered seismograms were re-sampled with a sampling frequency of $1 \mathrm{~Hz}$. For each time step of the array analysis, we analyzed seismograms in a 60-s lapse time window, which was subsequently set at 15 -s intervals in the re-sampled continuous seismograms.

If coherent waves with semblance values larger than 0.5 were observed in at least five arrays, the original epicenters were estimated according to the above-mentioned procedure. The assumed epicenters for the grid search were set with one-degree spacing in latitude and longitude in and around Japan. After we had identified the optimum epicenter locations through the grid search and steepest descent methods, we adopted only the estimated epicenters with a cylindrical-wave index larger than 0.99 and a plane-wave index smaller than 0.85 as well-determined epicenters.

\section{Spatiotemporal Distribution of VLFEs in Japan}

We show here an example of a seismogram and the results of our analysis for a 1-h-long record containing an ordinary earthquake and VLFEs. Band-pass filtered and high-pass filtered seismograms are shown in Fig. 1(a) and (b), respectively. The ordinary earthquake can be recog- 


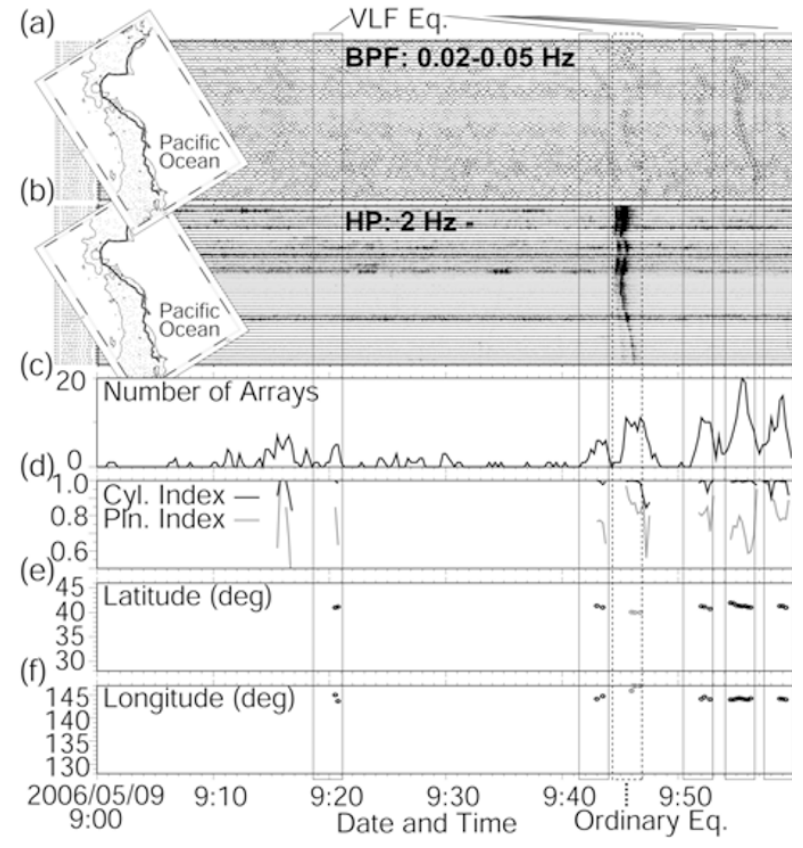

Fig. 1. An example of seismograms and results of the analysis. Seismograms observed at stations near the Pacific coast are shown. (a) Band-pass filter and (b) high-pass filter are applied to these seismograms. Obtained (c) number of arrays with semblance coefficients larger than 0.5 , (d) cylindrical- and plane-wave indexes, (e) latitude, and (f) longitude of the estimated epicenter at each time step. Solid and dashed rectangles denote VLF and ordinary earthquakes, respectively.

nized in both the seismograms; however, VLFEs with lowfrequency energies smaller than $0.1 \mathrm{~Hz}$ can be detected only in the band-pass-filtered seismogram (Fig. 1(a)). Coherent energy arrivals were detected in more than five arrays in the energy arrivals (Fig. 1(c)), and the epicenters could be estimated with large cylindrical- and small plane-wave indexes (Figs. 1(d-f)). An ordinary earthquake listed in the catalogue provided by the Japan Meteorological Agency (JMA) is also shown in Fig. 1; however, a VLFE observed with a larger amplitude in low-frequency ranges than that of the ordinary earthquake is not listed. Further, it is expected that ordinary earthquakes can be removed from all of the detected events using the JMA catalogue because the capability of the JMA to detect ordinary earthquakes is higher than that of the analytical approach used here.

The spatial and spatiotemporal distributions of the detected events are shown in Fig. 2. In our analysis, approximately 15,000 counts were obtained for VLFEs. The epicenters were distributed along the NT and in the Tokachioki region around the junction of the Japan Trench (JT) and Kuril Trench (KT) (Fig. 2(a)). These VLFEs along the NT were distributed near the trough, which is a seismically active area of shallow VLFEs (e.g., Obara and Ito, 2005); no event corresponding to deep VLFEs (Ito et al., 2007) were detected with large cylindrical-wave and small plane-wave indexes.

We defined a count as a single detection in a lapse time window. In Kii-hanto-nanto-oki along the NT and Tokachioki, VLFE activities started immediately after the occurrences of the 2004 Kii-hanto-nanto-oki $(M=7.4)$ and the 2003 Tokachi-oki $(M=8.0)$ earthquakes, respectively

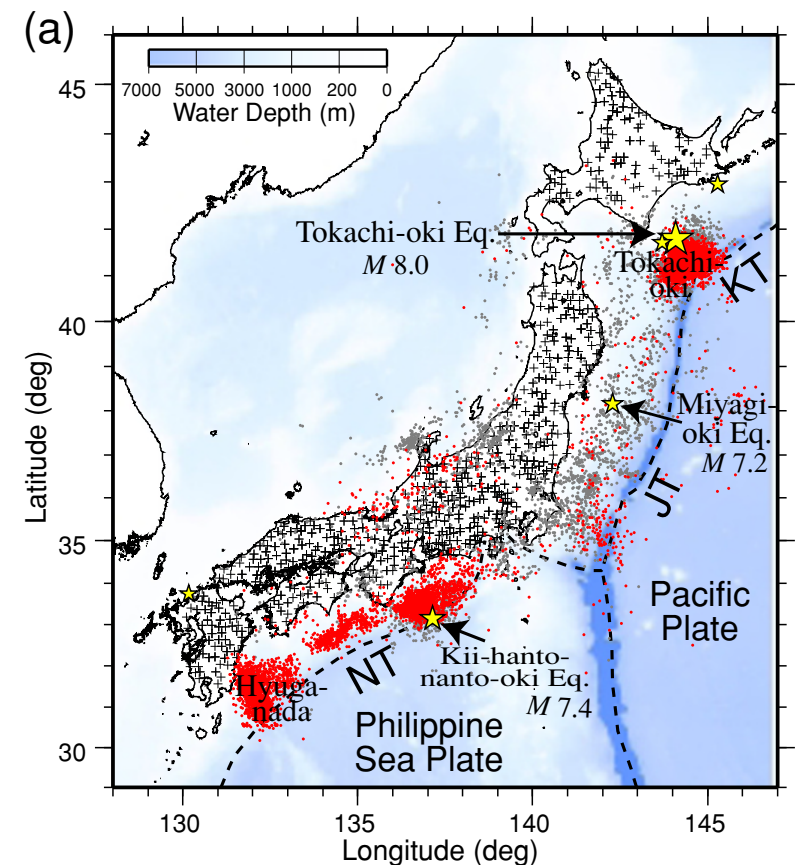

(b) Tokachi-oki eq. nanii-hanto-- Kki eq. Miyagi-oki eq.

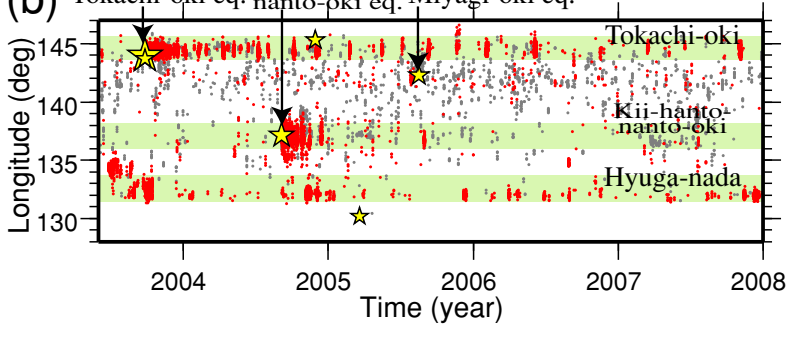

Fig. 2. (a) Spatial and (b) spatiotemporal distributions of detected events. Gray and red dots denote events corresponding to the earthquakes listed in the JMA catalogue and other earthquakes, respectively; these earthquakes are mainly VLFEs. Tiltmeter stations and earthquakes with magnitudes larger than 7.0 are denoted by crosses and stars, respectively.

(Fig. 2(b)). These VLFE activities in both regions were quite active at the beginning and have been decreasing in proportion to the lapse time since the mainshocks. Therefore, these VLFEs may be caused by stress concentration in seismogenic regions of VLFEs due to the large earthquakes and, consequently, both the activities will decrease as the accumulated strain is released. We obtained 3000 counts in Kii-hanto-nanto-oki and 8500 counts in Tokachi-oki, which accounted for more than $75 \%$ of the detected VLFEs all over Japan. This result suggests that the above-mentioned mechanism may be one of the most important causes of VLFEs. On the other hand, in the Hyuga-nada region along the NT, approximately 2500 counts of VLFEs have occurred during the last 5 years despite the absence of earthquakes (Fig. 2(b)). Therefore, other stress-concentration processes apart from neighboring large earthquakes may exist and cause such activity.

VLFEs in Kii-hanto-nanto-oki and Hyuga-nada along the NT have been well investigated (Obara and Ito, 2005; Ito and Obara, 2006). Ito and Obara (2006) estimated the centroid moment tensors of VLFEs that occurred along the NT and showed that the centroids were distributed in accretionary prisms along the trough, and that the focal mech- 
anisms were consistent with the fault geometries of out-ofsequence thrusts (e.g., Moore et al., 1990) and mega-splay faults (e.g., Park et al., 2002) in the prism. In contrast, we report here for the first time the occurrence of VLFEs in Tokachi-oki. It is known that there are no accretion prisms and that tectonic erosion of the trench margin occurs along the western KT and JT (e.g., von Huene and Culotta, 1989). In Section 5 we discuss how VLFEs occur under such a tectonic setting.

\section{Possible Mechanisms of VLFEs in Tokachi-oki}

In order to discuss the detailed location of VLFE activity in Tokachi-oki, we first have to compare the accuracy of the epicenter locations. We compared the epicenter locations of our results with those in the JMA catalogue for ordinary earthquakes. Although the epicenter locations of off-shore earthquakes determined by the JMA without ocean bottom seismometers are generally not very accurate, it is expected that the epicenter locations in the catalogue will be more accurate than those obtained in our analysis. We investigated the distribution of the differences between the epicenter obtained in our results and the JMA epicenters for 154 earthquakes in Tokachi-oki. The averages and standard deviations of the differences show the biases of our results and the random uncertainty, respectively. The averages are $0.248^{\circ}$ and $-0.002^{\circ}$, and the standard deviations are $0.251^{\circ}$ and $0.231^{\circ}$ in longitude and latitude, respectively.

The spatial distribution of the count density of the detected VLFEs is shown in Fig. 3(a). The location of the peak count density is represented by a small cross. In this distribution of epicenters, the averages of the differences are $144.382^{\circ} \mathrm{E}$ and $41.314^{\circ} \mathrm{N}$, and the standard deviations are $0.242^{\circ}$ and $0.147^{\circ}$ in longitude and latitude, respectively. These standard deviations are not larger than the estimation uncertainty discussed above, suggesting that the true locations of VLFEs in Tokachi-oki are concentrated in a relatively small area and that the broad distribution of the count density is mainly due to the random uncertainty in our epicenter estimation.

Using the JMA epicenters, we can also correct the location of the peak count density according to the bias in our epicenters. The corrected peak is located approximately $50 \mathrm{~km}$ northwest of the junction of the KT and JT, where the depth of the plate boundary is approximately $15 \mathrm{~km}$ (Fig. 3(a)). The co-seismic ruptured area of the 2003 Tokachi-oki earthquake (Yagi, 2004) and its aftershocks with thrust-type mechanisms (Ito et al., 2004) are mainly distributed up to at least $30 \mathrm{~km}$ north of the corrected peak and at depths of approximately $20 \mathrm{~km}$ and deeper. It is interpreted that the up-dip and down-dip limits of the seismogenic zone are related to the transition depth of the rock frictional property (e.g., Scholz, 1998). The depth of the updip limit is about $20 \mathrm{~km}$ according to the previous results on the co-seismic slip and aftershock distributions. Therefore, the plate boundary around the VLFE activity is shallower than the up-dip limit of the seismogenic zone. Although the depth of VLFE activity could not be estimated in our analysis, the VLFE activity that we did detect may occur in localized patches with a relatively larger shear strength than their surroundings, where stable sliding occurs along (a)
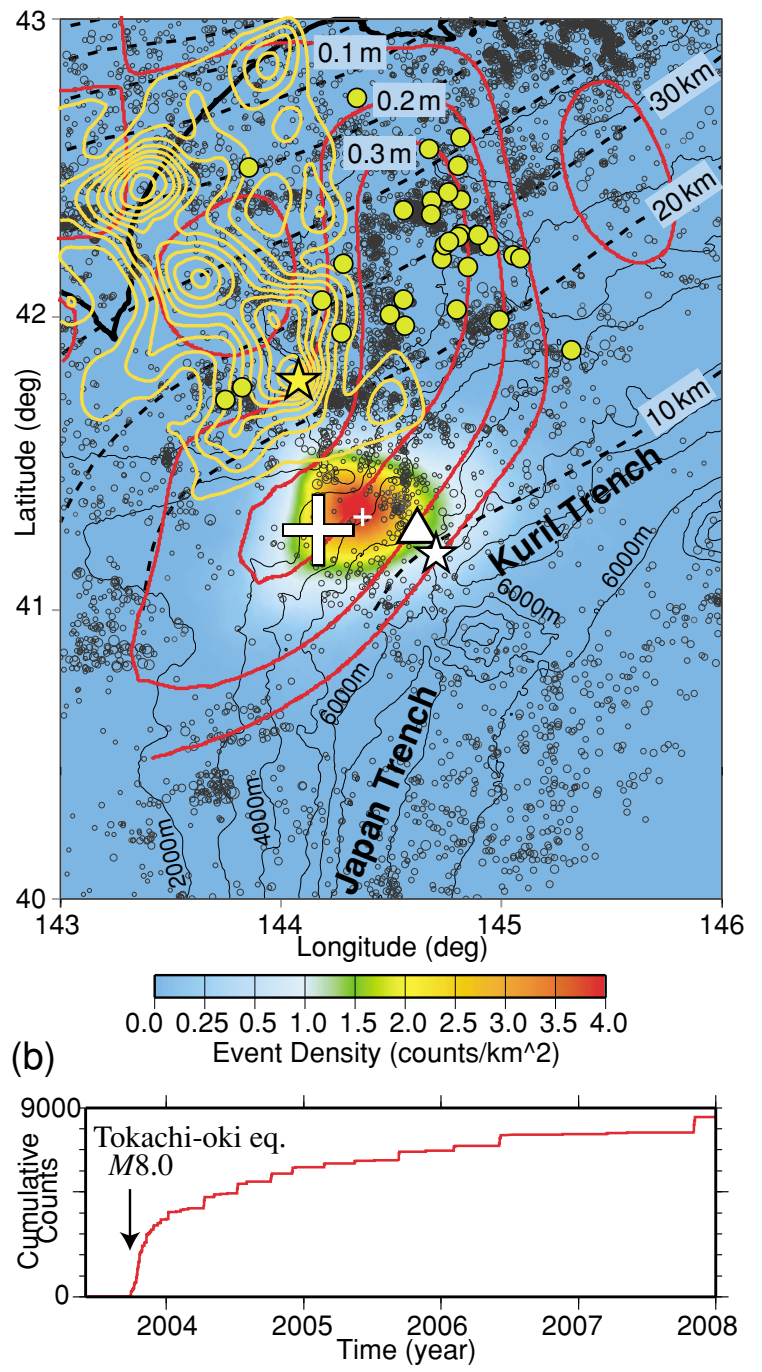

Fig. 3. (a) Spatial distribution of count density and (b) cumulative number of counts of VLFEs in Tokachi-oki. The original and corrected peaks of count density are respectively shown by small and large crosses. Yellow and red contours represent the co-seismic (Yagi, 2004) and the post-seismic (Miyazaki et al., 2004) slips. The 2003 mainshock epicenter is shown by a yellow star. Epicenters of the earthquakes in the JMA catalogue and large aftershocks with the thrust-type mechanism (Ito et al., 2004) are indicated by black and green circles, respectively. The triangle and white stars denote the subducted seamount and the LF earthquakes (Obara et al., 2004), respectively. Black dashed lines show depth distribution of the plate boundary (Earthquake Research Committee, 2003).

the shallow portion of the plate boundary.

Two low-frequency (LF) earthquakes in Tokachi-oki were detected and investigated using the moment tensor analysis of Obara et al. (2004) (Fig. 3(a)). These researchers showed that the LF earthquakes having thrusttype mechanisms occurred on the plate boundary near the trenches and also pointed out that their centroids were located near a subducted seamount (Yamazaki and Okamura, 1989) that could be strongly coupled with the overriding plate and act as an asperity. Further, the LF earthquakes were interpreted to be slips that occurred on the decollement at the top of the subducted seamount. The VLFE activity detected in our study is also located near this subducted 
seamount (Fig. 3(a)). Therefore, the subducted seamount may be related to a VLFE resulting from a mechanism similar to that of the LF earthquakes discussed by Obara et al. (2004).

It is also known that subducted seamounts cause deformations in the overriding plate. Dominguez et al. (1998) investigated the deformation properties by performing sandbox experiments and showed that backthrusts in the overriding plate are formed landward of the subducted seamount. These backthrusts can also be causative faults of the VLFEs distributed landward of the subducted seamount. Stress change caused by the mainshock and the following postseismic slip may promote slips on such intraplate faults.

The epicenters of VLFEs are also distributed in the post-seismic slip area of the 2003 Tokachi-oki earthquake (Miyazaki et al., 2004) (Fig. 3(a)). We have presented two possible models of VLFEs: the plate-boundary model and the intra-plate model. In both cases, stress change caused by the mainshock and the following post-seismic slip can load the seismogenic region of VLFEs. In particular, the localized and isolated asperity, whose surroundings are stably sliding by the post-seismic slip, on the plate boundary is likely to slip as VLFEs, with seismicity being related to the post-seismic slip rate. The temporal change in the cumulative count number of VLFEs (Fig. 3(b)) is qualitatively consistent with the temporal evolution of the post-seismic slip.

\section{Conclusions}

We analyzed tilltmeter data using an array signalprocessing technique with the objective of detecting and locating VLFEs. The VLFEs obtained in our analysis, covering the period of the last 5 years, are distributed not only along the NT but also in Tokachi-oki near the junction of the JT and KT without developed accretionary prisms. Therefore, the mechanism of VLFEs in Tokachi-oki may be different from that of VLFEs in the NT. We propose two possible models for the VLFE occurrence in Tokachi-oki: (1) the plate-boundary model in which VLFEs occur on a shallower portion of the plate boundary than the seismogenic region of ordinary earthquakes; (2) the intra-plate model in which VLFEs occur on faults in the overriding plate. Although it is difficult to choose between the models because the depths and the focal mechanisms were not obtained in our analysis, in both models it is expected that the 2003 mainshock and its post-seismic slip will lead to the accumulation of strain in the localized seismogenic area and cause VLFEs. A temporal change in the cumulative number of VLFEs in this area qualitatively supports this interpretation.

Acknowledgments. We used the hypocenter catalogue provided by the Japan Meteorological Agency (JMA) and bathymetrical data provided by the Japan Oceanographic Data Center. S.
Schwartz and Y. Murai provided thoughtful reviews, which improved this manuscript. All the figures in this paper are drawn using GMT (Wessel and Smith, 1998).

\section{References}

Dominguez, S., S. E. Lallemand, J. Malavieille, and R. von Huene, Upper plate deformation associated with seamount subduction, Tectonophysics, 293, 207-224, 1998.

Earthquake Research Committee, Long-term evaluation of earthquakes along the Kuril trench, http://www.jishin.go.jp/main/chousa/ kaikou_pdf/chishima.pdf, The Headquarters for Earthquake Research Promotion, 2003.

Ito, Y. and K. Obara, Dynamic deformation of the accretionary prism excites very low frequency earthquakes, Geophys. Res. Lett., 33, L02311, doi:10.1029/2005GL025270, 2006.

Ito, Y., H. Matsubayashi, H. Kimura, T. Matsumoto, Y. Asano, and S. Sekiguchi, Spatial distribution for moment tensor solutions of the 2003 Tokachi-oki earthquake $\left(M_{\mathrm{w}}=7.9\right)$ and aftershocks, Earth Planets Space, 56, 301-306, 2004

Ito, Y., K. Obara, K. Shiomi, S. Sekine, and H. Hirose, Slow earthquakes coincident with episodic tremors and slow slip events, Science, 315, 503-506, 2007.

Miyazaki, S., P. Segall, J. Fukuda, and T. Kato, Space-time distribution of afterslip following the 2003 Tokachi-oki earthquake: Implications for variations in fault zone frictional properties, Geophys. Res. Lett., 31, L06623, doi:10.1029/2003GL019410, 2004.

Moore, G., T. Shipley, P. Stoffa, D. Karig, A. Taira, S. Kuramoto, H. Tokuyama, and K. Suyehiro, Structure of the Nankai Trough accretionary zone from multichannel seismic reflection data, J. Geophys. Res., 95, 8753-8765, 1990.

Neidell, N. S. and M. T. Taner, Semblance and other coherency measures for multichannel data, Geophysics, 36, 482-497, 1971.

Obara, K., Nonvolcanic deep tremor associated with subduction in southwest Japan, Science, 296, 1679-1681, 2002.

Obara, K. and Y. Ito, Very low frequency earthquakes excited by the 2004 off the Kii peninsula earthquakes: A dynamic deformation process in the large accretionary prism, Earth Planets Space, 57, 321-326, 2005.

Obara, K., Y. Haryu, Y. Ito, and K. Shiomi, Low frequency events occurred during the sequence of aftershock activity of the 2003 Tokachi-Oki earthquake; a dynamic process of the tectonic erosion by subducted seamount, Earth Planets Space, 56, 347-351, 2004.

Obara, K., K. Kasahara, S. Hori, and Y. Okada, A densely distributed highsensitivity seismograph network in Japan: Hi-net by National Research Institute for Earth Science and Disaster Prevention, Rev. Sci. Inst., 76, 021301, doi:10.1063/1.1854197, 2005.

Park, J. O., T. Tsuru, S. Kodaira, P. R. Cummins, and Y. Kaneda, Splay fault branching along the Nankai subduction zone, Science, 297, 11571160, 2002.

Press, W. H., S. A. Teukolsky, W. T. Vetterling, and B. P. Flannery, Numerical recipes: The art of scientific computing FORTRAN version, 702 pp., Cambridge Univ. Press, Cambridge, 1989.

Scholz, C. H., Earthquakes and friction laws, Nature, 391, 37-42, 1998.

von Huene, R. and R. Culotta, Tectonic erosion at the front of the Japan Trench convergent margin, Tectonophysics, 160, 75-90, 1989.

Wessel, P. and W. H. F. Smith, New, improved version of the Generic Mapping Tools released, Eos Trans. AGU, 79, 579, 1998.

Yagi, Y., Source rupture process of the 2003 Tokachi-oki earthquake determined by joint inversion of teleseismic body wave and strong ground motion data, Earth Planets Space, 56, 311-316, 2004.

Yamazaki, T. and Y. Okamura, Subducting seamounts and deformation of overriding forearc wedges around Japan, Tectonophysics, 160, 207-229, 1989.

Y. Asano (e-mail: asano@bosai.go.jp), K. Obara, and Y. Ito 